\title{
The Influence of Yoga Teaching Model reform on College Students' Physical Quality under the Objective of Application-Oriented Training
}

\author{
Zhenxiang Tian, Yang Li* \\ Zaozhuang University \\ Zaozhuang, China \\ Zhenxiang9292@163.com
}

\begin{abstract}
As the goal of deepening the training of ordinary colleges and universities, the goal of physical education in colleges and universities is not only to improve the physical quality of students, but also to make students form a sense of "lifelong sports." In order to meet students' individual character development and interests, realize the goal of physical education in colleges and universities, this paper conducts the optional yoga course teaching mode reform of preliminary experiment, the results show that the experimental class teaching effect evaluation is better than that in comparative classes, and the flexibility and balance of college students' physical fitness is significantly better than that of students in the comparative class. It is suggested that the reform of teaching mode is conducive to the improvement of students' physical education quality.
\end{abstract}

Keywords_Yoga; Applied; Teaching model; Physical quality

\section{INTRODUCTION}

Nowadays, most ordinary university sports curriculum in colleges and universities teaching method, teaching organization form, teaching system mainly by a single, traditional college physical education is given priority to, and how to improve the students' technical ability is given priority to, teacher play its dominant too much, while ignoring the students' subjectivity. With students' physique is declining in recent years, however, the teaching aim of college sports in colleges and universities is not only to improve the students' physical quality, more to let the students form a "lifetime sports" consciousness and adhere to the "life is movement, movement is science" of exercise. Therefore, the traditional sports teaching mode can not meet the needs of fostering talent, at the same time also can't meet students' individual character development and the interest hobby, difficult to achieve the goal of physical education in colleges and universities.

Therefore, the physical education teaching should keep renewing the teaching concept, strengthen the innovation and research and development of the curriculum, and change the traditional physical education teaching methods that are uniformed, indoctrinated and modeled.[1] On this basis, the school should pay attention to practical ability of students participate in sports activities and interests, strengthen the reform of college physical education teaching at the same time, keep with the time advancement of trend, and formulate conforms to the contemporary college students that meet the needs of physical education teaching idea, teaching personnel training mode, physical education teaching contents, course system, etc; Build is able to let the teachers play a leading role, and can satisfy the need of students' subjective initiative of teaching mode, so as to fully arouse the enthusiasm of students, train students' technical teaching and practical ability, to enrich college sports teaching content, teaching mode, improve the teaching quality and promote the harmonious development of students body and mind has a great significance.

Along with the university sports education in colleges and universities to wide attention of the theory of lifetime sports, and applied talents training mode and the penetration effect of diversified culture, many colleges and universities has gradually to yoga classes on the university sports teaching content. However, due to the immature development of the curriculum, there are many problems in college physical yoga teaching at present. Students only pay attention to imitation and ignore the integration of yoga thoughts. Limited space and so on, affect the teaching effect and the sustainable development of yoga. Many scholars at home and abroad on the status quo of yoga teaching mode analysis are mainly concentrated in the following two aspects: blind reference for calisthenics, gymnastics and other traditional teaching model ignores the particularity of yoga teaching; It only focuses on the operating elements that influence the process of yoga teaching mode, and ignores the learning of education guiding ideology and yoga theoretical basis [2].

This paper proposes a new teaching model reform based on the current situation of yoga teaching model, and provides an effective way to realize the reform of college physical education teaching under the goal of cultivating applicationoriented talents. Colleges and universities cultivate applied talents, should not only have mature technical skills directly applied to practical work, the more the need to develop discipline essence rule, using skills learned to develop deeper and broader social and cultural and economic value. College sports education goal should actively respond to applied talents training target, make the teaching process give full play to the students' ability of autonomous learning, teachers guided based on self exploration and practice, transfer from teachers to learners learning process action technology into learners 
actively construct self action structure and applied to actual teaching process, to promote the national sports, interest in sports, lifelong sports [3]. Therefore, in the process of teaching reform, we should pay attention to teaching practice and social practice, so that students can feel the charm of yoga while really falling in love with yoga, and have the ability to spread yoga and develop yoga.

\section{RESEARCH OBJECTS AND METHODS}

\section{A. Subjects}

The students of two classes in the sophomore year of a college physical yoga option course, class one for 50, are all female. All students have not participated in yoga training and guidance before the experiment, all of them are the first time to learn yoga.

\section{B. Research program}

Content: 2.1 teaching Yoga itself is a large and complex system, is divided into different genres, at present more popular mainly include: Hatha Yoga, Astangha Yoga, Iyengar Yoga, Hot Yoga, Flow Yoga, etc. According to the college physical education syllabus, this study chooses hatha yoga with low difficulty coefficient, which is suitable for beginners. The movement combination is coherent, suitable for the development of students creativity flow yoga, as well as the embodiment of mutual cooperation, mutual promotion, mutual practice of double yoga as the main content of teaching.

Teaching mode: this paper selects one teaching class as the experimental class for the reform of teaching mode, and one teaching class as the comparison class for the teaching effect. The same teacher USES the same teaching equipment and venue to teach the same teaching content for two semesters. The comparison class adopts the conventional teaching mode, mainly teaching by teachers. Teachers lead students to practice breathing and body posture in the classroom, and implement the teaching plan according to the teaching outline. Experimental classes of teaching model reform, taking students as the main body of the teaching mode, through the guidance of teachers, let the students to self construction and explore the action of movement and the theory of knowledge learning yoga postures. After each class to join the movements of yoga teaching practice, let every student can have the opportunity to lead the class students to practice the individual potential, to further consolidate the learned movement, causes the student to learn yoga at the same time improve the understanding of yoga and self-expression, performance ability. At the end of the semester, I will arrange teaching practice and social practice, and arrange yoga association activities. If you are interested, I can arrange to work as an intern coach in the gym for in-depth practice and experience yoga teaching 。

Teaching effect assessment: yoga option class total teaching hours for 32 weeks, in two semesters, yoga option class teaching content is given priority to with hatha yoga, for sun salutations (primary) and sun salutation (intermediate). The teaching effect is evaluated at the end of the semester, which is divided into two parts: body quality test and yoga action test score. According to the teaching syllabus, the requirements of the examination syllabus and the evaluation criteria of the college yoga options course, the assessment team composed of professional teachers will evaluate and score the students of different groups. The research papers of the students' satisfaction with the course were designed according to the teaching effect of the experimental class and the comparison class.

Physical fitness test: the flexibility test (i.e., the anterior flexion of the sitting body) is conducted using the standard anterior flexion test instrument of the sitting body.(2) the power quality index (grip) : right hand holding dynamometer test subjects who body kept upright, arms keep integrity power grip strength test, grip strength index = grip strength $(\mathrm{kg}) / \mathrm{body}$ weight $(\mathrm{kg})$ by 100 . Balance quality (occlusion single foot station): the physical condition of college students is tested by the instrument, which directly records the standing time. The body composition (percentage of body fat and waist-to-hip ratio): the body composition of the subject is directly determined by using the body composition tester based on the experimental principle of bioelectrical impedance.

Data statistics: all data were processed by SPSS17.0, expressed as mean value plus or minus standard deviation, and $\mathrm{T}$ test was adopted for comparison between groups.

\section{RESEARCH RESULTS AND ANALYSIS}

A. Comparison of teaching effect evaluation of students 1) Comparison of students' physical qualities

TABLE I COMPARISON OF THE TEST RESULTS OF STUDENTS' PHYSICAL FITNESS

\begin{tabular}{|c|c|c|c|c|c|}
\hline group & $\begin{array}{l}\text { Flexible } \\
\text { quality }\end{array}$ & Power quality & $\begin{array}{l}\text { Balance } \\
\text { quality }\end{array}$ & $\begin{array}{l}\text { Body fat } \\
\text { percentage }\end{array}$ & $\begin{array}{l}\text { Waist-to-hip } \\
\text { ratio }\end{array}$ \\
\hline control group & $13.3 \pm 5.80$ & $13.2 \pm 6.67$ & $9.35 \pm 6.89$ & $20.48 \pm 4.27$ & $0.76 \pm 8.54$ \\
\hline experimental & $17.4 \pm 7.99$ & $14.3 \pm 7.23$ & $11.7 \pm 9.18$ & $19.16 \pm 5.61$ & $0.71 \pm 9.60$ \\
\hline
\end{tabular}

group

Essential teaching goal of college physical education curriculum is to improve student's physical quality, and yoga asana practice through the body's bend, stretch, lift, pressure stretching each part of the body's muscles, joints, ligaments and 
were combined with breathing exercises. Flexible, quality is the foundation of yoga exercise, one of the students was tested by ZuoWeiTi proneness of flexible quality, results from the study show that yoga studies through the year flexible quality is better than the control group $(\mathrm{P}<0.01)$. Power quality test USES the grip strength index, grip strength index = grip strength $(\mathrm{kg}) /$ body weight $(\mathrm{kg})$ x 100 , index score more than 20 points, 75, $74 \sim 7017$ points, $69 \sim 63$ (16 points, 62-56 15 points, $55 \sim 5113$ points, $50 \sim 4112$ points, 10 points under 40.The results showed that there was no significant difference in strength quality between the two groups, but the level of the experimental group was higher than that of the control group.
Balance quality is also one of an important exercise in yoga asana practice aspects, this experiment adopts the eye closure of one foot stand up the test results show that the experimental group scored significantly better than the control group, with very significant difference $(\mathrm{P}<0.01)$. Body composition was measured by body composition meter to obtain body fat percentage and waist/hip ratio, and the results showed no significant difference between the control group and the experimental group.

2) Comparison of students' yoga movement scores

TABLE II

COMPARISON OF STUDENTS' YOGA ACTION SCORES

\begin{tabular}{ll}
\hline group & Yoga movement score \\
\hline control group & $78 \pm 4.5$ \\
experimental group & $80 \pm 6.48$ \\
\hline
\end{tabular}

At the end of the semester is composed of professional teachers assessment team of two groups of students to complete their yoga action evaluation score, out of 100 , the main content is the salutation is A, comparison results show that the experimental group yoga postures scored significantly higher than that of control group, with significant difference $(\mathrm{P}$ $<0.01)$. It suggests that students in the experimental group have a good command of yoga movements.

\section{B. Comparison of student satisfaction}

In this experiment, students were asked to evaluate their learning effect satisfactorily through four indicators, namely "body and mind pleasure", "flexibility and coordination", "selfcognition" and "learning and creation ability". The results showed that the self-satisfaction of the experimental group was significantly higher than that of the control group.

\section{CONCLUSION}

\section{A. Analysis of traditional yoga teaching model}

University physical education curriculum of institutions of higher learning in traditional teaching mode can meet some students who really love yoga, and it's often difficult for students in the excitability to combine body, mind and spirit organically together through the guidance of teachers. Real yoga practice is when breathing, consciousness and posture are combined. Traditional yoga teaching focuses too much on the difficulty of posture and ignores the unity of students' subjectivity and body and mind.

B. The reform of yoga teaching mode under the training mode of application-oriented talents is helpful to the improvement of college students' sports accomplishment

Through the improvement of the teaching mode to improve students' learning participation enthusiasm, stimulate the search for new things, and to attract students, let students in teaching and learning process, not only better achieve the teaching purpose, at the same time, individual thinking ability, expression ability, ability also got comprehensive performance. This ability to understand and understand the main points of sports activities is of great significance and value to the implementation of lifelong sports under the training goal of application-oriented talents [4]. The results of this study also shows that the teaching model reform significantly improve student evaluation of teaching effect and the improvement of physical quality, increase the understanding of yoga and comprehension, enhance the level of the college students' sports accomplishment.

\section{REFERENCES}

[1] Zhang Hong. Research on the application of smart phone and "Internet + " teaching model in yoga teaching $[\mathrm{J}]$. Journal of guangzhou sports university,2017(2):56-56.

[2] Iyengar. The light of yoga [M]. Beijing: Beijing branch of the world book publishing company,2005, 1:1-40.

[3] Zhou Jiao. Research on the application of discovery teaching model in yoga teaching -- a case study of yoga club of school of business, shanxi university [J]. Exercise,2013(4):74-75.

[4] Zhang Maomao. Construction and practical research on the teaching model of college sports teams based on constructivism -- taking yoga teaching as an example.[J]. Journal of nanjing sports university.2014.2(28):76-80. 